Article

\title{
Tiamulin-Resistant Mutants of the Thermophilic Bacterium Thermus thermophilus
}

\author{
Erin E. Killeavy ${ }^{1}$, Gerwald Jogl ${ }^{2}$ (I) and Steven T. Gregory ${ }^{1, *}$ \\ 1 Department of Cell and Molecular Biology, The University of Rhode Island, Kingston, RI 02881, USA; \\ erin_killeavy@my.uri.edu \\ 2 Department of Molecular Biology, Cell Biology and Biochemistry, Brown University, \\ Providence, RI 02912, USA; gerwald_jogl@brown.edu \\ * Correspondence: stgregory@uri.edu; Tel.: +1-401-874-5947
}

Received: 28 April 2020; Accepted: 5 June 2020; Published: 9 June 2020

\begin{abstract}
Tiamulin is a semisynthetic pleuromutilin antibiotic that binds to the $50 \mathrm{~S}$ ribosomal subunit A site and whose (((2-diethylamino)ethyl)thio)-acetic acid tail extends into the P site to interfere with peptide bond formation. We have isolated spontaneous tiamulin-resistant mutants of the thermophilic bacterium Thermus thermophilus, containing either single amino acid substitutions in ribosomal protein $\mathrm{uL} 3$ or single base substitutions in the peptidyltransferase active site of $23 \mathrm{~S}$ rRNA. These mutations are consistent with those found in other organisms and are in close proximity to the crystallographically determined tiamulin binding site. We also conducted a cross-resistance analysis of nine other single-base substitutions in or near the peptidyltransferase active site, previously selected for resistance to structurally unrelated antibiotics. While some of the base substitutions in 23S rRNA are positioned to directly affect tiamulin-ribosome contacts, others are some distance from the tiamulin binding site, indicating an indirect mechanism of resistance. Similarly, amino acid substitutions in uL3 are predicted to act indirectly by destabilizing rRNA conformation in the active site. We interpret these observations in light of the available ribosome X-ray crystal structures. These results provide a more comprehensive profile of tiamulin resistance caused by mutations in the bacterial ribosome.
\end{abstract}

Keywords: tiamulin; peptidyltransferase; ribosome; rRNA; ribosomal protein; antibiotic resistance mutation; Thermus thermophilus

\section{Introduction}

The ribosomal peptidyltransferase active site (also referred to as the PTC), the site of peptide bond formation during protein synthesis, is the target of a number of structurally unrelated classes of antibiotics, and mutations conferring resistance to many of these drugs have been identified in the genes encoding $23 \mathrm{~S}$ rRNA or ribosomal proteins from a wide range of organisms. Advances in structural biology have led to numerous high-resolution structures of ribosomes in complex with antibiotics, providing a wealth of information about the mechanisms of action of these important drugs and facilitating predictions about mechanisms of antibiotic resistance reviewed by [1-3].

The pleuromutilin class of antibiotics, the first of which was isolated from the fungus Pleurotus mutilis [4], includes the semi-synthetic derivatives tiamulin, repatamulin, and valnemulin, and are used primarily in veterinary medicine reviewed by [5]. Based on chemical footprinting of $23 \mathrm{~S}$ rRNA in Escherichia coli ribosomes, pleuromutilins bind to the PTC and compete for binding with the 16-atom macrolide and peptidyltransferase inhibitor carbomycin (though not with the 14-atom macrolide erythromycin) [6], and thereby inhibit peptide bond formation [7]. The precise nature of pleuromutilin binding to the ribosome was subsequently determined by X-ray crystallography of ribosome-drug 
complexes [8-10]. Tiamulin interacts exclusively with rRNA residues, although ribosomal protein uL3 is in close proximity to the tiamulin binding site without making direct contact with the drug.

Tiamulin-resistant mutants with altered ribosomal proteins were first identified in E. coli, although the exact nature of the mutations was not determined [11]. Subsequent studies of several organisms, including E. coli [12,13], Brachyspira spp. [14], and Staphylococcus aureus [15,16], found resistance to result from amino acid substitutions in ribosomal protein uL3. Ribosomal protein uL3 consists of a globular domain situated on the 50S subunit surface, and an extended loop that reaches deep into the subunit where it approaches the PTC [17-20]. Amino acid substitutions conferring tiamulin resistance occur in this loop and presumably confer resistance by affecting local rRNA conformation. Resistance results from reduced binding, as indicated by chemical footprinting of mutant ribosomes from Brachyspira spp. [14]. Consistent with chemical probing data, tiamulin-resistance also results from base substitutions in 23S rRNA in and around the PTC of several organisms, including E. coli [12], Brachyspira spp. [14], S. aureus [16], Mycobacterium smegmatis [21], and Mycoplasma gallisepticum [22].

Both the chemical probing data and the nature of mutations can to some extent be rationalized given the X-ray crystal structures of pleuromutilins in complex with ribosomes from either the bacterium Deinococcus radiodurans [8,9] or the archaeon Haloarcula marismortui [10]. Several base substitutions in $23 \mathrm{~S}$ rRNA occur at sites of drug contact and presumably lead to reduced binding affinity. Amino acid substitutions in uL3 occur at residues in close proximity to some of these same $23 \mathrm{~S}$ rRNA residues, suggesting indirect effects on RNA conformation as the mechanism of resistance. While binding of pleuromutilins protects some bases (U2506, U2584, U2585) in close proximity to the drug from chemical probes, it enhances reactivity of others (A2058 and A2059), more distant from the drug binding site, suggesting that drug binding can induce conformational changes [6]. It also suggests that substitutions of bases not in the immediate vicinity of tiamulin could confer drug resistance by indirect means.

In order to more extensively characterize the basis for pleuromutilin resistance, we isolated spontaneous tiamulin-resistant mutants of the thermophilic bacterium Thermus thermophilus and tested for cross-resistance to tiamulin a number of mutants with base substitutions in the PTC previously selected for resistance to other antibiotics [23]. This organism has proven to be a good model system for the study of antibiotic-resistance mutations with the ability to combine facile genetics, biochemistry, and crystallography of its ribosomes [24]. Building upon previous studies, these data provide a more comprehensive examination of tiamulin-resistance. By examining published crystal structures of tiamulin bound to the $50 \mathrm{~S}$ subunit of $D$. radiodurans [8] and H. marismortui [10], we assess the likely mechanism of resistance caused by these mutations. While base substitutions occur in the tiamulin binding pocket, others are located some distance away, supporting the hypothesis that pleuromutilin resistance can be caused by conformational changes due to mutations distant from the drug binding site, and that these mutations distort ribosome conformation.

\section{Results}

\subsection{Isolation of Spontaneous Tiamulin-Resistant Mutants}

In order to maximize the range of mutants arising in selections, we employed two different T. thermophilus strains, HB27 [25] and IB-21 [26], originally isolated from locations geographically remote from one another (Japan and Iceland, respectively) and having different optimal growth temperatures. These strains both contain two copies of each rRNA gene, but rapid gene conversion generally results in homoallelic mutants producing pure populations of mutant ribosomes [23]. We noted that temperature, strain, drug concentration, and media formulation, are all variables potentially influencing the spectrum of mutations isolated (our unpublished observations). We therefore selected tiamulin-resistant mutants at either 65 or $72{ }^{\circ} \mathrm{C}$ and at 50,100, or $200 \mu \mathrm{g} / \mathrm{mL}$. Mutants and their selections are listed in Table 1 .

Based on the known binding site of tiamulin in the PTC, as well as previously described tiamulinresistant mutants, we PCR amplified and sequenced the corresponding regions of the $r r l A$ and $r r l B$ 
genes encoding $23 \mathrm{~S}$ rRNA and the rplC gene encoding ribosomal protein uL3. We identified two mutations in rplC, CGC to either CAC or TGC, that result in either of two amino acid substitutions at the same position, $\mathrm{R} 149 \mathrm{H}$ or R149C of uL3 (E. coli numbering used throughout; corresponding to R144 in the T. thermophilus sequence; Figure 1a). These were selected on 50 and $100 \mu \mathrm{g} / \mathrm{mL}$ tiamulin. Amino acid substitutions at this and surrounding positions have been identified in other species [12-16]. We also identified a total of six different base substitutions in the 23S rRNA in the PTC. Among these were G2061A, G2061U, A2451U, C2452U, U2500A, and U2504G. We had previously identified several of these (G2061A, C2452U, U2500A, and U2504G) in selections for mutants resistant to chloramphenicol [23], but have not previously observed the G2061U and A2451U substitutions in T. thermophilus. A2451U is particularly noteworthy as having been described previously only in mouse mitochondria [27] and Mycobacterium smegmatis [28].

Table 1. Spontaneous tiamulin-resistant mutants identified in this study.

\begin{tabular}{|c|c|c|c|c|}
\hline Strain & Genotype & Mutation & Tiamulin Selection & Temperature \\
\hline IB-21 & $r p l C-\mathrm{R} 149 \mathrm{H}$ & uL3-R149H & $50 \mu \mathrm{g} / \mathrm{mL}$ & $72{ }^{\circ} \mathrm{C}$ \\
\hline IB-21 & rplC-R149C & uL3-R149C & $100 \mu \mathrm{g} / \mathrm{mL}$ & $72{ }^{\circ} \mathrm{C}$ \\
\hline HB27 & rplC-R149C & uL3-R149C & $100 \mu \mathrm{g} / \mathrm{mL}$ & $72{ }^{\circ} \mathrm{C}$ \\
\hline IB-21 & $\operatorname{rrlAB-G2061\mathrm {A}}$ & 23S-G2061A & $50,100 \mu \mathrm{g} / \mathrm{mL}$ & $72{ }^{\circ} \mathrm{C}$ \\
\hline HB27 & $r r l A B-G 2061 \mathrm{~A}$ & 23S-G2061A & $100 \mu \mathrm{g} / \mathrm{mL}$ & $65^{\circ} \mathrm{C}$ \\
\hline IB-21 & $r r l A B-G 2061 \mathrm{U}$ & 23S-G2061U & $100 \mu \mathrm{g} / \mathrm{mL}$ & $62{ }^{\circ} \mathrm{C}$ \\
\hline HB27 & $\operatorname{rrlAB-G2061U}$ & 23S-G2061U & $100 \mu \mathrm{g} / \mathrm{mL}$ & $72{ }^{\circ} \mathrm{C}$ \\
\hline HB27 & $\operatorname{rrlAB}-\mathrm{A} 2451 \mathrm{U}$ & 23S-A2451U & $100 \mu \mathrm{g} / \mathrm{mL}$ & $72{ }^{\circ} \mathrm{C}$ \\
\hline IB-21 & $r r l A B-C 2452 \mathrm{U}$ & 23S-C2452U & $50 \mu \mathrm{g} / \mathrm{mL}$ & $72{ }^{\circ} \mathrm{C}$ \\
\hline IB-21 & rrlAB-U2500A & 23S-U2500A & $100,200 \mu \mathrm{g} / \mathrm{mL}$ & $72{ }^{\circ} \mathrm{C}$ \\
\hline HB27 & rrlAB-U2500A & 23S-U2500A & $50 \mu \mathrm{g} / \mathrm{mL}$ & $65^{\circ} \mathrm{C}$ \\
\hline IB-21 & $r r l A B-\mathrm{U} 2504 \mathrm{G}$ & 23S-U2504G & $100 \mu \mathrm{g} / \mathrm{mL}$ & $62{ }^{\circ} \mathrm{C}$ \\
\hline HB27 & $r r l A B-\mathrm{U} 2504 \mathrm{G}$ & 23S-U2504G & $200 \mu \mathrm{g} / \mathrm{mL}$ & $72{ }^{\circ} \mathrm{C}$ \\
\hline
\end{tabular}

E. coli numbering used throughout. Mutants were selected on TMG medium containing tiamulin at the indicated concentrations and at the temperature indicated.
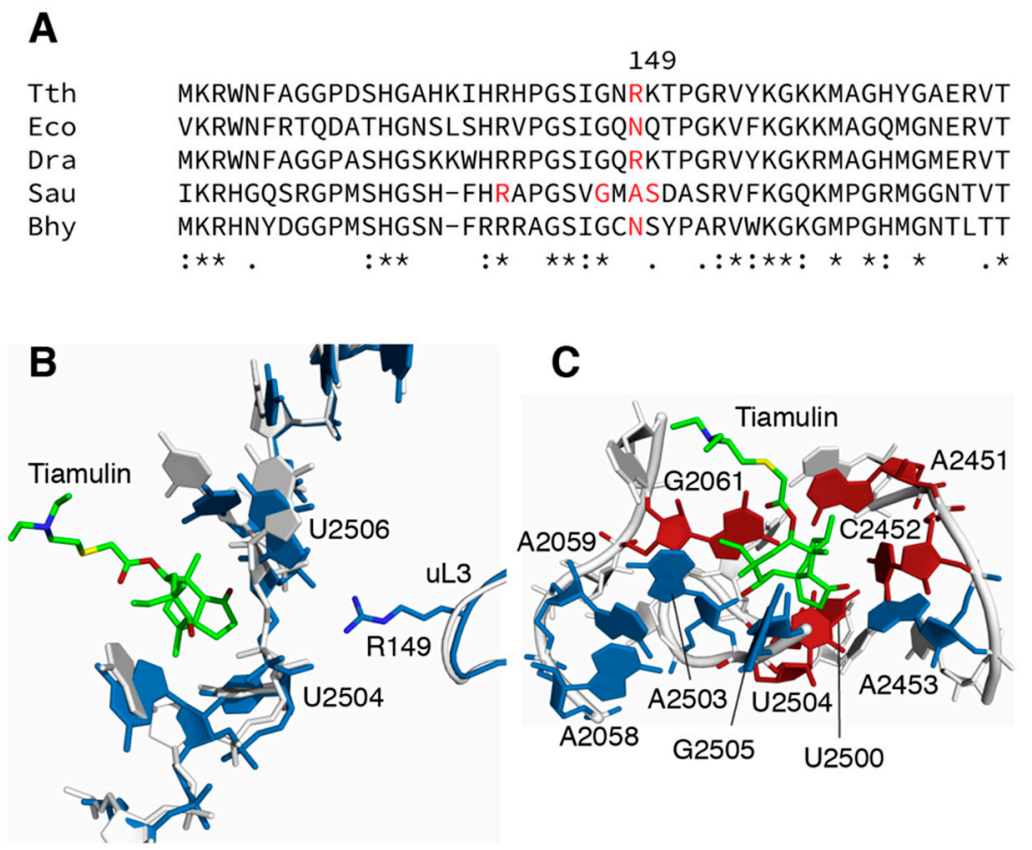

Figure 1. Sites of mutations and inferred mechanisms of resistance. (A) Sequence alignment of ribosomal protein $\mathrm{uL} 3$ encompassing the sites of mutations identified in this study. Uses organisms for whom tiamulin-resistance mutations in uL3 have been found. Tth, Thermus thermophilus (Accession number Q72I04); Dra, Deinococcus radiodurans (Accession number Q9RXK2); Eco, Escherichia coli (Accession 
number P60438); Sau, Staphylococcus aureus (Accession number P60449); Bhy, Brachyspira hyodysenteriae (Accession number A0A2K9JGD3) (B) Interaction of ribosomal protein uL3 and 23S rRNA at the tiamulin binding site, based on the crystal structures of ribosomes from T. thermophilus (PDB entry 4y4p.cif; 36) and D. radiodurans (PDB entry 1xbp.cif; 8). Structures were aligned and images rendered using PyMOL (Schrodinger). R149 is within hydrogen bonding distance of the 2' hydroxyl of U2504 and the phosphate oxygen of U2506. (C) Interactions between tiamulin and 23S rRNA in the D. radiodurans (PDB entry 1xbp.cif; 8) 50S subunit structure. Sites of mutation conferring resistance are colored red, sites of mutations not conferring resistance are colored blue.

To demonstrate a direct causal relationship between mutation and resistance phenotype, wild-type T. thermophilus was transformed with genomic DNA from the resistant mutants, selecting tiamulin resistance and then confirming the presence of the original mutation by sequencing. In all cases, transformants contained the originally selected tiamulin-resistance mutation, indicating a causal relationship between mutation and phenotype.

\subsection{Resistance Phenotypes}

We estimated comparative resistance to tiamulin using a disc diffusion assay (Table 2; see Section 4). As controls, assays were also performed using the $30 \mathrm{~S}$ subunit antibiotic streptomycin, the DNA gyrase inhibitor ciprofloxacin, and the cell wall synthesis inhibitor ampicillin. These analyses provide a crude, semi-quantitative measure of relative drug resistance. Ribosomal protein uL3 mutants conferred the lowest level of tiamulin resistance, exhibiting significant inhibition zones, while all of the 23S rRNA mutants were generally more resistant. For instance, G2061A, G2061U, A2451U, U2500, and U2504G showed no zones of inhibition. The possibility that lack of inhibition due to thermal degradation of tiamulin during prolonged incubation of slow-growing mutants can be excluded since discs pre-incubated at $72{ }^{\circ} \mathrm{C}$ for 1 week show no decrease in inhibition zone against wild-type T. thermophilus.

Table 2. Cross-resistance phenotypes of tiamulin-resistant mutants.

\begin{tabular}{|c|c|c|c|c|c|c|c|c|c|c|c|c|c|c|}
\hline \multirow{2}{*}{ Mutant } & \multicolumn{14}{|c|}{ Zone of Inhibition (mm) } \\
\hline & Tam & Ery & Clr & Rox & Azm & Mid & Tyl & Spi & Lin & Chl & Str & Rif & Amp & Cip \\
\hline WT (IB-21) & 30 & 27 & 36 & 32 & 22 & 21 & 36 & 16 & 36 & 29 & 14 & 17 & 40 & 22 \\
\hline uL3-R149H & 16 & 23 & 33 & 28 & 18 & 25 & 39 & 10 & 44 & 38 & 15 & 17 & 45 & 20 \\
\hline uL3-R149C & 17 & 25 & 36 & 32 & 22 & 23 & 38 & 12 & 35 & 31 & 17 & 16 & 51 & 25 \\
\hline 23S-G2061U & - & 22 & 35 & 24 & 11 & 24 & 48 & 13 & 7 & 9 & 17 & 17 & 50 & 25 \\
\hline 23S-A2451U & - & 12 & 33 & 28 & 15 & 28 & 64 & 27 & - & - & 30 & 21 & 50 & 26 \\
\hline 23S-C2452U & - & 14 & 25 & 20 & 10 & 20 & 48 & 13 & 20 & 9 & 16 & 15 & 42 & 22 \\
\hline 23S-U2500A & - & 14 & 20 & 19 & 11 & 12 & 36 & 7 & 18 & 15 & 15 & 17 & 40 & 21 \\
\hline 23S-U2504G & - & 18 & 34 & 28 & 13 & 18 & 46 & 16 & 22 & - & 16 & 16 & 42 & 22 \\
\hline
\end{tabular}

All mutants are derived from IB-21 with the exception of the 23S rRNA-A2451U mutant, which is derived from HB27. Additionally, included are mutants obtained in a previous study, all derived from IB-21. Tam, tiamulin; Ery, erythromycin; Clr, clarithromycin; Rox, roxithromycin; Azm, azithromycin; Mid, midecamycin; Tyl, tylosin; Spi, spiramycin; Lin, lincomycin; Chl, chloramphenicol; Str, streptomycin; Rif, rifampicin; Amp, ampicillin; Cip, ciprofloxacin. Discs were $6 \mathrm{~mm}$, such that a zone of $6 \mathrm{~mm}$ indicates no inhibition (indicated by -). Due to the high frequency of reversion, the G2061A mutant was grown in the presence of chloramphenicol. Blue, strong resistance (complete or nearly complete absence of inhibition zone); light blue, weak resistance ( $50 \%$ or greater reduction in inhibition zone).

We examined the cross-resistance phenotypes of PTC mutants to various 50 S subunit inhibitors binding at or near the peptidyltransferase active site. In addition to tiamulin, we tested sensitivity to the 14-atom macrolides erythromycin, clarithromycin, roxithromycin, the 15-atom macrolide azithromycin, the 16-atom macrolides midecamycin, tylosin, and spiramycin, the lincosamide 
lincomycin, and chloramphenicol. Ampicillin and the DNA gyrase inhibitor ciprofloxacin were included for comparison. Results from these tests are shown in Table 2.

The uL3 mutations produce no cross resistance to other drugs that bind to this region and were specific for tiamulin. We previously identified chloramphenicol-resistant or macrolide-resistant mutants of T. thermophilus containing single base substitutions in the vicinity of the PTC [23]. As several of these same base substitutions were identified in selections for tiamulin-resistant mutants in the current study, we examined a number of available PTC mutants for resistance to tiamulin. These included A2058G, A2059G, G2447A, A2453G, U2500C, A2503G, U2504C, U2504A, and G2505A. Of these, the only ones found to confer tiamulin resistance were G2447A and U2504A, which confer weak resistance (16 and $17 \mathrm{~mm}$ zones of inhibition, respectively), at levels comparable to those produced by the uL3 mutations. Since U2504 was identified in our initial selections, only G2447A was not identified in selections for tiamulin resistance. This suggests that our initial selections were close to exhaustive.

\subsection{Resistance to Other PTC-Binding Antibiotics}

A large number of antibiotics target the PTC, and we examined our tiamulin-resistant mutants for cross-resistance to a broad range of drugs. Most notable is the consistent hypersensitivity of the G2061A mutant to macrolides, but not to tiamulin, lincomycin, or chloramphenicol. While this could be accounted for as a result of the extremely slow growth rate of this mutant, the A2451U mutant does not show this same level of hypersensitivity, despite also being very slow growing. This latter mutant shows hypersensitivity to the 16-atom macrolide tylosin and resistance to lincomycin and chloramphenicol. The isolation of A2451U as a tiamulin-resistance mutation showing cross resistance to chloramphenicol is perhaps significant as base substitutions at A2451 have previously been isolated as chloramphenicol-resistance mutations in mouse mitochondria [27] and found to confer chloramphenicol resistance after site-directed mutagenesis of Mycobacterium smegmatis [28].

Base substitutions at U2504 produce varying phenotypes, depending on the actual base substitution. Thus, U2504G confers complete tiamulin resistance (and was identified as a spontaneous tiamulin-resistant mutant), while U2504A confers minimal resistance and U2504C confers no resistance at all. Base substitutions at U2504 also exhibit varied responses to either lincomycin or the 16-atom macrolide tylosin, with U2504G conferring resistance, U2504C conferring only weak resistance, and U2504A conferring hypersensitivity. In contrast, all three base substitutions confer chloramphenicol resistance and were previously identified in selections for chloramphenicol resistance [23].

\section{Discussion}

Amino acid substitutions in uL3 conferring tiamulin resistance have been found in several organisms, including E. coli, S. aureus, and Brachyspira spp. Currently there are crystal structures of tiamulin bound to ribosomes from two sources, D. radiodurans [8] and H. marismortui [10]. In neither case is uL3 positioned to make direct contact with tiamulin (Figure 1b), indicating that the mechanism of resistance conferred by uL3 mutations is indirect, presumably via some perturbation of rRNA conformation. While the $D$. radiodurans structure does not show sidechains for ribosomal protein uL3 [8], structures of the T. thermophilus ribosome shows the $\delta$-guanidinium group of R149 of uL3 to be within $3 \AA$ of a phosphate oxygen of U2506 of 23S rRNA [29]. A site-directed mutagenesis study of E. coli uL3 [13] found that, while N149S and N149D substitutions confer resistance (the latter confirming previous studies of spontaneous mutants), N149R does not, consistent with the presence of an arginine at this position in the wild-type T. thermophilus uL3. However, examination of the crystal structure of the E. coli ribosome [20] or the cryo-EM structure of the S. aureus ribosome [30] indicates that neither the asparagine residue at position 149 of E. coli nor the alanine at position 149 of S. aureus uL3 are in position to make a direct contact with $23 S$ rRNA. Other amino acid substitutions found in uL3 of tiamulin-resistant S. aureus are R141S, G147R, A149L, S150L, and D151Y $[15,16]$. Therefore, the means by which mutations at $\mathrm{N} 149$ of E. coli or A149 of S. aureus uL3 confer resistance is not clear, as neither of these residues are in position to interact with $23 \mathrm{~S}$ rRNA as does the arginine in T. thermophilus uL3. 
All of the base substitutions conferring tiamulin resistance occur at universally or nearly universally conserved positions (Table 3), suggesting that each of these residues plays an important role in catalysis, rRNA folding, or stabilizing the structure in a catalytically active conformation. It therefore follows that base substitutions in the active site could perturb the structure sufficiently to impact tiamulin binding affinity. There is currently no crystal structure of the T. thermophilus ribosome in complex with tiamulin, so structural interpretations are based on examination of crystal structures of the D. radiodurans [8] and H. marismortui [10] 50 S subunit-tiamulin complexes.

Table 3. Closest approaches of $23 \mathrm{~S}$ rRNA bases and tiamulin.

\begin{tabular}{|c|c|c|c|c|c|}
\hline Mutation & $\begin{array}{c}\text { Tiamulin } \\
\text { Phenotype }^{1}\end{array}$ & Conservation & Nearest Neighbor & $\begin{array}{l}\text { Distance } \\
\text { (Dra, ̊) }\end{array}$ & $\begin{array}{l}\text { Distance } \\
\text { (Hma, ̊) }\end{array}$ \\
\hline A2058G & $S$ & $98.33 / 42.28$ & A2058-N6:Tam-O2 & 7.1 & 7.1 \\
\hline A2059G & $S$ & $99.17 / 99.41$ & A2059-N1:Tam-O2 & 6.7 & 5.8 \\
\hline G2061A,U & $R, R$ & $100.00 / 99.88$ & G2061-N2:Tam-O4 & 3.0 & 3.0 \\
\hline G2447A & $\mathrm{R}$ & $96.28 / 98.20$ & G2447-N1:Tam-C8 & 5.3 & 5.0 \\
\hline A2451U & $\mathrm{R}$ & $100.00 / 100.00$ & A2451-N6:Tam-C7 & 3.6 & 3.3 \\
\hline C2452U & $\mathrm{R}$ & $100.00 / 100.00$ & $\begin{array}{l}\text { C2452-C1':Tam-O1 } \\
\text { C2452-O2:Tam-O1 }\end{array}$ & $\begin{array}{l}3.9 \\
4.0\end{array}$ & $\begin{array}{l}4.7 \\
2.9\end{array}$ \\
\hline A2453G & S & $99.59 / 82.39$ & A2453-N3:Tam-C2 & 6.0 & 6.6 \\
\hline U2500A,C & $\mathrm{R}, \mathrm{S}$ & $100.00 / 99.64$ & $\begin{array}{l}\text { U2500-O2:Tam-C1 } \\
\text { U2500-O2:Tam-C2 }\end{array}$ & $\begin{array}{l}7.2 \\
7.4\end{array}$ & $\begin{array}{l}6.4 \\
6.1\end{array}$ \\
\hline A2503G & $S$ & $99.59 / 98.31$ & $\begin{array}{l}\text { A2503-O2':Tam-C17 } \\
\text { A2503-C8:Tam-O2 }\end{array}$ & $\begin{array}{l}3.0 \\
-\end{array}$ & $\begin{array}{l}4.0 \\
3.0\end{array}$ \\
\hline U2504G,C,A & $\mathrm{R}, \mathrm{S}, \mathrm{R}$ & $99.59 / 98.43$ & $\begin{array}{l}\text { U2504-C5:Tam-C1 } \\
\text { U2504-O2':Tam-C2 }\end{array}$ & $\begin{array}{l}3.5 \\
5.0\end{array}$ & $\begin{array}{l}5.6 \\
3.0\end{array}$ \\
\hline
\end{tabular}

${ }^{1} \mathrm{~S}$, sensitive; R, resistant. Distance based on PDB entries 1xbp.cif for D. radiodurans (Dra) [8] and 3g4s.cif for H. marismortui (Hma) [10].

While the exact effects of base substitutions on the structure of rRNA in the PTC are difficult to predict, all the mutants are viable, indicating that the conformation of the mutant active sites must sufficiently resemble the native structure to permit catalysis of peptide bond formation. What the crystal structures do provide is an approximation of the closest approach of mutated residues and tiamulin (Table 3). While some differences between the two structures are evident, some interpretation regarding mechanisms of resistance is still possible.

There is a rough correlation between the proximity of mutated residues to tiamulin and the resistance phenotype; mutated residues near the tiamulin binding site are more likely to cause resistance than mutated residues at more remote positions (Figure 1c). Thus, substitutions at A2058 and A2059, which are between 6 and $7 \AA$ from tiamulin, fail to confer resistance, leaving unresolved the question of enhanced chemical reactivity of A2058 upon tiamulin binding [6]. It is worth noting that U2504G confers resistance to both tiamulin and chloramphenicol, while disrupting the contact of uL3 with the nearby U2506 confers only tiamulin resistance, suggesting that the latter mutation has less of an impact on the local structure. This is also consistent with the higher level of tiamulin resistance conferred by the U2504G substitution.

A2451 is the 23S rRNA residue closest to the site of peptide bond formation, as first revealed by the crystal structure of the H. marismortui $50 \mathrm{~S}$ subunit [31]. A2451 is a universally conserved nucleotide [32] and only two other instances of viable mutants having base substitutions at this position have been reported [27,28]; substitutions at A2451 produce dominantly lethal phenotypes in Escherichia coli [33]. A2451 is under $4 \AA$ from tiamulin but does not appear to make direct contact. A2503G and G2505A, originally isolated as chloramphenicol-resistance mutations, do not confer tiamulin resistance despite being within $3 \AA$ of tiamulin. The nearest approach to tiamulin by A2503 is via the C8, and would thus not be influenced by an A to G transition. The nearest approach from G2505 is via the backbone, and similar would not necessarily be affected by a base substitution. 
Several of the mutations cannot be explained by direct loss of antibiotic-ribosome contact. G2447's closest approach to tiamulin is about $5 \AA$ and U2500 roughly $7 \AA$. Substitutions at these positions could perturb the structure sufficiently to diminish binding without propagating throughout the active site, and thereby having drastic effects on peptide-bond forming ability. The ability of base substitutions in the PTC to confer resistance despite being remote from the drug binding site has been observed before $[34,35]$. The idea that pleuromutilins bind via an induced-fit mechanism has been proposed based on X-ray crystal structures [35]. The enhanced reactivity of A2058 to chemical probes suggests an indirect influence of tiamulin on the conformation of these residues. These observations further emphasize the ability of antibiotic-resistance mutations to exert their effects from a position remote from the antibiotic binding site. More detailed structural analyses will be necessary to uncover the precise basis for resistance caused by individual mutations.

\section{Materials and Methods}

\subsection{Bacterial Strains and Cultivation}

All mutants were derived from the T. thermophilus strains HB27 (ATCC BAA-163) [25] or IB-21 [26]. All strains were grown in TEM (Thermus Enhanced Medium, ATCC Medium 1598) or plated on TMG medium (identical to TEM with the exception of $0.5 \mathrm{~g} / \mathrm{L} \mathrm{CaCl}_{2}$ and lacking phosphate buffer) solidified with Gellam Gum (PlantMedia). Antibiotics were from the author's collection or were purchased from Sigma-Aldrich Chemical Corp.

\subsection{Isolation of Spontaneous Mutants}

To isolate mutants, overnight cultures originating from single colonies were grown in TEM overnight to saturation, and $10^{9}$ cells were plated onto TMG plates containing tiamulin at 50, 100, or $200 \mu \mathrm{g} / \mathrm{mL}$. Mutants derived from either of the two T. thermophilus strains, IB-21 or HB27, were isolated at 62,65 , or $72{ }^{\circ} \mathrm{C}$. After several days, mutant colonies appearing on selection plates were streaked for isolation on the same selection medium. Colonies arising on restreaks were streaked a second time on TMG plates without antibiotic. Single colonies were used to inoculate overnight cultures in TEM, grown to saturation, archived as glycerol stocks, and harvested for genomic DNA preps using the Wizard Genomic DNA kit (Promega) or the PureLink genomic DNA kit (Invitrogen).

\subsection{Analysis of Mutants}

PCR amplification of the $r p l C$ locus or the PTC region of $r r l A$ and $r r l B$ was performed using OneTaq DNA Polymerase (New England Biolabs). The $r p l C$ locus encoding ribosomal protein uL3 was amplified using oligonucleotide primers (IDT) Tth_rplC-fwd1 (5'-GAGCACTTTGAGCTGCGC ACCCACAACC- $3^{\prime}$ ) and Tth_rplC-rev2 (5'-GTGTGCTTCTGCG GCCAGATCTTCCGGC-3') and sequenced using primers Tth_rplC-fwd1 and Tth_rplC_rev1. The $r r l A$ and $r r l B$ loci were amplified using primer pair Tth-23S-E (5'-CGCCAAGGAACTCTGCAAGTTGGC-3') and Tth-23S-F (5'-CCAGA GGTGCGTCCCTTCCG GTCC-3') and sequenced using primers Tth-23S-E and Tth-23S-F. Sequencing was performed at the University of Rhode Island Genomics and Sequencing Center.

To confirm that the mutations identified by sequencing were actually responsible for the resistance phenotypes, wild-type T. thermophilus was transformed with genomic DNA, selecting the original phenotype. Transformants were purified, gDNA was extracted, and the presence of the original mutations were confirmed by PCR and sequencing.

\subsection{Disc Diffusion Assays}

To measure antibiotic resistance, $100 \mu \mathrm{L}$ of a saturated overnight culture (approximately $10^{8}$ cells) was plated onto a series of TMG plates. Onto the center of each plate was placed a $6 \mathrm{~mm}$ filter-paper disc (Whatman No. 2017-006) containing antibiotic. Concentrations used were as follows: tiamulin, erythromycin, clarithromycin, roxithromycin, azithromycin, midecamycin, tylosin, 
spiramycin, lincomycin, chloramphenicol, streptomycin, rifampicin, ciprofloxacin all $100 \mu \mathrm{g}$; and ampicillin, $20 \mu \mathrm{g}$. Plates were incubated overnight at 65 or $72{ }^{\circ} \mathrm{C}$. The diameter of zones of inhibition were measured in millimeters.

\section{Conclusions}

The results described here provide a more comprehensive description of tiamulin-resistance mutations than previously observed in a single system. Given the amenability of ribosomes from T. thermophilus to crystallization and structure determination, these mutants should provide an important resource for establishing the precise mechanism of resistance to tiamulin at the atomic level.

Author Contributions: Conceptualization, S.T.G.; isolation and analysis of mutants, E.E.K.; structural analysis, E.E.K., S.T.G. and G.J.; writing, review, and editing, E.E.K., S.T.G. and G.J.; funding acquisition, S.T.G. and G.J. All authors have read and agreed to the published version of the manuscript.

Funding: This research was funded by National Institutes of Health, grant number GM094157 to G.J. and S.T.G., and by USDA National Institute of Food and Agriculture, Hatch Formula project 1016013 to S.T.G.

Acknowledgments: The authors are grateful to J. Atoyan and the URI Genomics and Sequencing Center for assistance with DNA sequencing, and to Marianne Prior for logistical support.

Conflicts of Interest: The authors declare no conflict of interest.

\section{References}

1. Wilson, D.N. Ribosome-targeting antibiotics and mechanisms of bacterial resistance. Nat. Rev. Microbiol. 2014, 12, 35-48. [CrossRef] [PubMed]

2. Matzov, D.; Bashan, A.; Yonath, A. A bright future for antibiotics? Annu. Rev. Biochem. 2017, 86, 567-583. [CrossRef] [PubMed]

3. Lin, J.; Zhou, D.; Steitz, T.A.; Polikanov, Y.S.; Gagnon, M.G. Ribosome-targeting antibiotics: Modes of action, mechanisms of resistance, and implications for drug design. Annu. Rev. Biochem. 2018, 87, 451-478. [CrossRef] [PubMed]

4. Kavanagh, F.; Hervey, A.; Robbins, W.J. Antibiotic substances from Basidiomycetes: VIII Pleurotus mutilus (Fr.) Sacc. and Pleurotus passeckerianus pilat. Proc. Natl. Acad. Sci. USA 1951, 37, 570-574. [CrossRef]

5. Paukner, S.; Riedl, R. Pleuromutilins: Potent drugs for resistant bugs-mode of action and resistance. Cold Spring Harb. Perspect. Med. 2017, 7, 27-110. [CrossRef]

6. Poulsen, S.M.; Karlsson, M.; Johansson, L.B.; Vester, B. The pleuromutilin drugs tiamulin and valnemulin bind to the RNA at the peptidyl transferases centre on the ribosome. Mol. Microbiol. 2001, 41, 1091-1099. [CrossRef]

7. Hodgin, L.A.; Högenauer, G. The mode of action of pleuromutilin derivatives. Effect on cell-free polypeptide synthesis. Eur. J. Biochem. 1974, 47, 527-533. [CrossRef]

8. Schlünzen, F.; Pyetan, E.; Fucini, P.; Yonath, A.; Harms, J.M. Inhibition of peptide bond formation by pleuromutilins: The structure of the $50 \mathrm{~S}$ ribosomal subunit from Deinococcus radiodurans in complex with tiamulin. Mol. Microbiol. 2004, 54, 1287-1294. [CrossRef]

9. Davidovich, C.; Bashan, A.; Auerbach-Nevo, T.; Yaggie, R.D.; Gontarek, R.R.; Yonath, A. Induced-fit tightens pleuromutilins binding to ribosomes and remote interactions enable their selectivity. Proc. Natl. Acad. Sci. USA 2007, 104, 4291-4296. [CrossRef]

10. Gürel, G.; Blaha, G.; Moore, P.B.; Steitz, T.A. U2504 determines the species specificity of the A-site cleft antibiotics: The structures of tiamulin, homoharringtonine, and bruceantin bound to the ribosome. J. Mol. Biol. 2009, 389, 146-156. [CrossRef]

11. Böck, A.; Turnowsky, F.; Högenauer, G. Tiamulin resistance mutations in Escherichia coli. J. Bacteriol. 1982, 151, 1253-1260. [CrossRef]

12. Bøsling, J.; Poulsen, S.M.; Vester, B.; Long, K.S. Resistance to the peptidyl transferase inhibitor tiamulin caused by mutation of ribosomal protein L3. Antimicrob. Agents Chemother. 2003, 47, 2892-2896. [CrossRef]

13. Klitgaard, R.N.; Ntokou, E.; Nørgaard, K.; Biltoft, D.; Hansen, L.H.; Traedholm, N.M.; Kongsted, J.; Vester, B. Mutations in the bacterial ribosomal protein L3 and their association with antibiotic resistance. Antimicrob. Agents Chemother. 2015, 59, 3518-3528. [CrossRef] [PubMed] 
14. Pringle, M.; Poehlsgaard, J.; Vester, B.; Long, K.S. Mutations in ribosomal protein L3 and 23 S ribosomal RNA at the peptidyl transferase centre are associated with reduced susceptibility to tiamulin in Brachyspira spp. isolates. Mol. Microbiol. 2004, 54, 1295-1306. [CrossRef]

15. Gentry, D.R.; Rittenhouse, S.F.; McCloskey, L.; Holmes, D.J. Stepwise exposure of Staphylococcus aureus to pleuromutilins is associated with stepwise acquisition of mutations in $r p l C$ and minimally affects susceptibility to retapamulin. Antimicrob. Agents Chemother. 2007, 51, 2048-2052. [CrossRef] [PubMed]

16. Miller, K.; Dunsmore, C.J.; Fishwick, C.W.; Chopra, I. Linezolid and tiamulin cross-resistance in Staphylococcus aureus mediated by point mutations in the peptidyl transferase center. Antimicrob. Agents Chemother. 2008, 52, 1737-1742. [CrossRef] [PubMed]

17. Ban, N.; Nissen, P.; Hansen, J.; Moore, P.B.; Steitz, T.A. The complete atomic structure of the large ribosomal subunit at $2.4 \AA$ resolution. Science 2000, 289, 905-920. [CrossRef]

18. Harms, J.; Schluenzen, F.; Zarivach, R.; Bashan, A.; Gat, S.; Agmon, I.; Bartels, H.; Franceschi, F.; Yonath, A. High resolution structure of the large ribosomal subunit from a mesophilic eubacterium. Cell 2001, 107, 679-688. [CrossRef]

19. Yusupov, M.M.; Yusupova, G.Z.; Baucom, A.; Lieberman, K.; Earnest, T.N.; Cate, J.H.; Noller, H.F. Crystal structure of the ribosome at $5.5 \AA$ resolution. Science 2001, 292, 883-896. [CrossRef]

20. Noeske, J.; Wasserman, M.R.; Terry, D.S.; Altman, R.B.; Blanchard, S.C.; Cate, J.H. High-resolution structure of the Escherichia coli ribosome. Nat. Struct. Mol. Biol. 2015, 22, 336-341. [CrossRef]

21. Long, K.S.; Poehlsgaard, J.; Hansen, L.H.; Hobbie, S.N.; Bottger, E.C.; Vester, B. Single $23 S$ rRNA mutations at the ribosomal peptidyl transferase centre confer resistance to valnemulin and other antibiotics in Mycobacterium smegmatis by perturbation of the drug binding pocket. Mol. Microbiol. 2009, 71, 1218-1227. [CrossRef]

22. Li, B.-B.; Shen, J.-Z.; Cao, X.-Y.; Wang, Y.; Dai, L.; Huang, S.-Y.; Wu, C.-M. Mutations in $23 S$ rRNA gene associated with decreased susceptibility to tiamulin and valnemulin in Mycoplasma gallisepticum. Fems Microbiol. Lett. 2010, 308, 144-149. [CrossRef]

23. Gregory, S.T.; Carr, J.F.; Rodriguez-Correa, D.; Dahlberg, A.E. 2005. Mutational analysis of $16 \mathrm{~S}$ and 23S rRNA genes of Thermus thermophilus. J. Bacteriol. 2005, 187, 4804-4812. [CrossRef] [PubMed]

24. Demirci, H.; Wang, L.; Murphy, F.V.; Murphy, E.L.; Carr, J.F.; Blanchard, S.C.; Jogl, G.; Dahlberg, A.E.; Gregory, S.T. The central role of protein S12 in organizing the structure of the decoding site of the ribosome. RNA 2013, 19, 1791-1801. [CrossRef] [PubMed]

25. Oshima, T.; Imahori, K. Description of Thermus thermophilus (Yoshida and Oshima) comb. nov., a nonsporulating thermophilic bacterium from a Japanese thermal spa. Int. J. Syst. Evol. Microbiol. 1974, 24, 102-112. [CrossRef]

26. Kristjansson, J.K.; Hreggvidsson, G.O.; Alfredsson, G.A. 1986. Isolation of halotolerant Thermus spp. from submarine hot springs in Iceland. Appl. Environ. Microbiol. 1986, 52, 1313-1316. [CrossRef]

27. Kearsey, S.E.; Craig, I.W. Altered ribosomal RNA genes in mitochondria from mammalian cells with chloramphenicol resistance. Nature 1981, 290, 607-608. [CrossRef]

28. Beringer, M.; Bruell, C.; Xiong, L.; Pfister, P.; Bieling, P.; Katunin, V.I.; Mankin, A.S.; Böttger, E.C.; Rodnina, M.V. Essential mechanisms in the catalysis of peptide bond formation on the ribosome. J. Biol. Chem. 2005, 280, 36065-36072. [CrossRef]

29. Selmer, M.; Dunham, C.M.; Murphy, F.V.; Weixlbaumer, A.; Petry, S.; Kelly, A.C.; Weir, J.R.; Ramakrishnan, V. Structure of the 70S ribosome complexed with mRNA and tRNA. Science 2006, 313, 1935-1942. [CrossRef]

30. Khusainov, I.; Vicens, Q.; Bochler, A.; Grosse, F.; Myasnikov, A.; Ménétret, J.F.; Chicher, J.; Marzi, S.; Romby, P.; Yusupova, G. Structure of the $70 \mathrm{~S}$ ribosome from human pathogen Staphylococcus aureus. Nucleic Acids Res. 2016, 44, 10491-10504. [CrossRef]

31. Nissen, P.; Hansen, J.; Ban, N.; Moore, P.B.; Steitz, T.A. The structural basis of ribosome activity in peptide bond formation. Science 2000, 289, 920-930. [CrossRef] [PubMed]

32. Cannone, J.J.; Subramanian, S.; Schnare, M.N.; Collett, J.R.; D'Souza, L.M.; Du, Y.; Feng, B.; Lin, N.; Madabusi, L.V.; Müller, K.M. The comparative RNA web (CRW) site: An online database of comparative sequence and structure information for ribosomal, intron and other RNA. BMC Bioinform. 2002, 3, 2.

33. Thompson, J.D.; Kim, D.F.; O'Connor, M.; Lieberman, K.R.; Bayfield, M.A.; Gregory, S.T.; Green, R.; Noller, H.F.; Dahlberg, A.E. Analysis of mutations at residues A2451 and G2447 of 23S rRNA in the peptidyltransferase active site of the 50S ribosomal subunit. Proc. Natl. Acad. Sci. USA 2001, 98, 9002-9007. [CrossRef] [PubMed] 
34. Blaha, G.; Gürel, G.; Schroeder, S.J.; Moore, P.B.; Steitz, T.A. Mutations outside the anisomycin-binding site can make ribosomes drug-resistant. J. Mol. Biol. 2008, 379, 505-519. [CrossRef]

35. Davidovitch, C.; Bashan, A.; Yonath, A. Structural basis for cross-resistance to ribosomal PTC antibiotics. Proc. Natl. Acad. Sci. USA 2008, 105, 20665-20670. [CrossRef] 